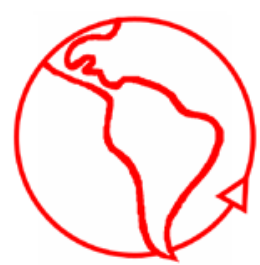

\title{
Constructivismo y sociología. Siete tesis de Bruno Latour
}

\author{
Constructivism and sociology. Seven theses of Bruno Latour
}

Pablo De Grande

Instituto de Investigación en Ciencias Sociales, Universidad del Salvador, Argentina.

Resumen

Bruno Latour postula que la sociología contemporánea se dedica en buena medida a explicar cómo ciertas configuraciones sociales (tales que las jerarquías de poder o las desigualdades estructurales) afectan el funcionamiento de otros ámbitos en sus contenidos no sociales (tales que el derecho, la religión o el arte). Como consecuencia de esto, la misma habría abandonado su misión primaria de explicar lo social por sí mismo, además de estar produciendo explicaciones repetitivas y poco interesantes. El presente artículo reúne elementos teóricos de diferentes obras de Bruno Latour en función de elaborar siete tesis sobre su crítica radical a la sociología contemporánea. La propuesta principal de Latour es reformular la investigación social, abriendo la 'caja negra' en la que lo social ha venido a convertirse. Finalmente se realizan algunas consideraciones sobre usos y limitaciones de las posiciones de Bruno Latour.

Palabras Clave: Constructivismo; Teoría Social; Micro- Macro; Teoría del Actor-Red; Reificación

\begin{abstract}
Bruno Latour argues that contemporary sociology is largely devoted to explain how certain social configurations (such as power hierarchies or structural inequalities) affect other non- social activities (such as law, religion or arts). As a result, sociology would have had abandoned its primary mission to explain the social itself, and it would be producing repetitive and uninteresting explanations. This paper puts together theoretical elements from different works of Bruno Latour in order to state seven theses on his radical critique to contemporary sociology. The main goal of Latour's proposal is reformulating social research, opening the black box in which the Social would have become. Finally, the article concludes summarizing usages and limitations of the perspective of Bruno Latour.
\end{abstract}

Keywords: Constructivism; Social Theory; Micro- Macro; Actor- Network Theory; Reification

\section{Introducción}

Este artículo propone retomar algunas nociones a partir de las cuales el autor francés Bruno Latour critica los modos en los que la sociología actual entiende sus prácticas y su objeto de estudio. Estos cuestionamientos están especialmente dirigidos a las perspectivas 'críticas' (Wuggenig 2008) y 'constructivistas' ${ }^{1}$, de las que tempranamente se

\footnotetext{
${ }^{1}$ El 'constructivismo' puede definirse como un espacio amplio de posiciones teóricas. López Pérez (2010) ve como los dos elementos más generales de los diferentes constructivismos el considerar que conocimiento y experiencia son elementos inseparables, y que entre uno hecho y su valoración no existe una relación única y necesaria. Para el caso de Latour, el constructivismo es a la vez un espacio de pertenencia y de problematización.
} 
diferenciara en sus investigaciones sobre la producción en el campo científico (Loredo Narciardi 2009: 117).

Latour buscar plantear en buena medida sus argumentos como alternativa y como denuncia a la sociología de Pierre Bourdieu, a la que culpa entre otras cosas de ser paternalista y condescendiente con su objeto de estudio. En este sentido, la identifica con el espíritu de la sociología clásica ('pre- relativista'), por venir a explicar a los actores lo que ellos no podrían ver, convirtiéndolos en agentes compelidos a actuar (por fuerzas ocultas) en formas que ni eligen ni comprenden (Schinkel 2007: 710).

Para organizar y presentar las posiciones de Latour, se postulan en este artículo siete afirmaciones presentadas por este autor, retomadas en este texto como una serie de tesis. En la obra de Latour las mismas no aparecen bajo el nombre de 'tesis', ni se agrupan de este modo, por lo que cabe aclarar el carácter sui generis de esta síntesis, que se da junto a la intención de mantener lo más ajustadamente posible su desarrollo al espíritu original del autor.

Si bien este artículo busca principalmente conectar algunas nociones desarrolladas por Bruno Latour en diferentes obras, cabe hacer algunos comentarios respecto a la relación polémica de este autor -especialmente en sus últimas producciones- con la obra de Pierre Bourdieu$^{2}$. Por momentos, la búsqueda del tono polémico, a veces radical, de Bruno Latour, toma a Bourdieu como blanco preferido de lo que Latour califica como una sociología que no vendría a explicar o a cuestionar sino a solidificar las relaciones sociales y de poder existentes (Schinkel 2007: 722). Latour parece en sentido retomar una figura algo caricaturizada de Bourdieu, pasando aparentemente por alto aquellos pasajes en los que Bourdieu abunda en recaudos y aclaraciones que difícilmente permitirían clasificarlo como un devoto determinista o un reduccionista de lo social a las relaciones de poder que la ciencia ilumine. Al decir Bourdieu por ejemplo que los esquemas y modelos de la teoría social...

no valen sino en tanto se los tenga por lo que son, es decir modelos lógicos que explican del modo al mismo tiempo más coherente y más económico el mayor número posible de hechos observados. Y que esos modelos se tornan falsos y peligrosos desde el momento en que se los trata como los principios reales de las prácticas, lo que equivale consustancialmente a sobreestimar la lógica de las prácticas y a dejar escapar aquello que constituye su verdadero principio. (Bourdieu 2007: 26).

...parece estar bastante lejos de ser alguien orientado a acercarse mecánicamente desde una teoría a un conjunto de casos para darlos por explicados de antemano.

Aclarado esto, también pueden señalarse algunas continuidades y puntos de contacto entre ambas miradas. Por una parte, Latour, al referirse a la 'trazabilidad' de las idiosincrasias individuales, a los orígenes rastreables de los gestos y las opiniones de cada sujeto, no parece señalar algo demasiado diferente al habitus de Bourdieu (Kindley 2010), levemente liberado de su anclaje de clase. Asimismo, también cabe señalar la centralidad de lo relacional (la relacionalidad) en ambas propuestas respecto de lo social y de la sociología misma, incluso si para Bourdieu lo relacional opera como un principio de oposición/diferenciación que permite dar sentido, mientras que Latour va encontrar las relaciones en redes complejas donde los opuestos son sólo una posibilidad. Por último, en ambos autores el estudio de la ciencia ha tenido un lugar destacado, habiendo producido

\footnotetext{
${ }^{2}$ Otra iniciativa de Latour, que no será retomada, es la de situar a su teoría como una continuación de la obra de Gabriel Tarde, planteada como injustamente derrotada por acción de Émile Durkheim y que sería recuperada por Latour en su teoría (Sánchez-Criado 2011).
} 
investigaciones y teorías específicas y generales a partir de las mismas (cf. Bourdieu 2007 2008; Latour 1992 1995).

Las siete tesis que serán desarrolladas en este artículo giran en torno a una preocupación central de Latour que se refleja en la primera tesis: que lo social debe, en cada caso, ser explicado, antes que ser algo que viene a explicar otros ámbitos de la vida humana. En este sentido, pone en duda la idea de que la distribución del poder social sea aquello que construye o da forma a las demás áreas de la vida humana: la religión, para la sociología, debe volverse algo más que el estudio de la dominación sacerdotal, el arte algo más que el estudio de las distinciones de clase por medio del arte, y así.

Las siguientes cuatro tesis vienen a dar especificidad a cómo es posible ampliar el campo de observación sociológica cuando lo social deja de ser algo que se da por conocido, es decir, cuando excede al problema del poder o de la organización del capital. Para ello, en las mismas amplía y detalla qué actores y objetos hasta ahora excluidos podrían entrar en las explicaciones de lo social.

Luego, las dos últimas tesis que se presentan complementan las cinco primeras desde una perspectiva de estrategia de investigación, en el terreno de la discusión macro- micro (a veces reformulada en la oposición acción- estructura, global- local).

A continuación se desarrollan las tesis mencionadas, sintetizando brevemente los argumentos del autor en torno a cada una de ellas.

\section{Tesis 1. Lo social debe ser explicado antes que venir a explicar}

La primera tesis que se expone consiste en afirmar que, en sociología, 'lo social' debe ser algo a explicar (Latour 2008: 21). Esta afirmación deriva de la incomodidad del autor con investigaciones que introducen 'lo social' (en el sentido de las relaciones de poder, de la desigualdad material, de la cultura o de 'la sociedad' en sentido impreciso) como lo que explica una situación, comportamiento o configuración particular.

En esta caracterización Latour describe un uso corriente de lo social a partir del cual la identificación de 'factores sociales' que expliquen los 'aspectos sociales' de un cierto fenómeno parece echar luz desde la sociología a cuestiones no sociales (Latour 2008: 16). La primera debilidad que este autor destaca de este procedimiento es que esta clase de sociología termina explicándolo todo, con excepción de 'lo social' propiamente dicho: al volverse la explicación por lo social una alusión a un contexto externo a los fenómenos (las 'condiciones de producción' del campo, la estructura social, las prácticas o el orden social, todos ellos subyacentes a lo observado), es dado como algo conocido y estable, como algo que ya no haría falta describir. Al mismo tiempo, cuando el sociólogo se acerca a cada ámbito que explica con este método se encuentra, según Latour, con dos problemas: uno de orden interno y otro de externo.

- El primero de ellos refiere a la sociología como campo de conocimiento. Esta dificultad consiste en que al proceder de dicha forma no se agrega información sobre qué es 'lo social'. Si bien se vuelve causa de cada vez más fenómenos, nunca es tarea del sociólogo explicarlo en sí mismo, ya que lo social operaría como una fuerza garantizada y omnipresente, pero inobservable en cada escenario práctico. Asociado a esto, Latour destaca una ausencia de falibilidad en estos procedimientos, aspecto incompatible con la producción de conocimiento científico. Dice Latour: "Ios informes textuales pueden fallar al igual que lo hacen a menudo los experimentos" (Latour 2008: 186). El cuestionario, la observación, la búsqueda bibliográfica, y finalmente el informar, igual que los experimentos de laboratorio, deberían -según Latour- reservarse la posibilidad de fallar, de no funcionar, de no haber sido adecuados para conocer o mostrar su objeto. Si lo 
social en cambio siempre está presente y siempre estructura las actividades humanas, sus fuerza explicativa nunca falla.

- El segundo es un problema de sustentabilidad externa del saber producido y se manifiesta cuando los actores explicados rechazan de plano las explicaciones obtenidas. Sea al negársele al religioso el carácter de real de sus divinidades, sea al afirmar que la obra de arte vale solamente por los mecanismos de prestigio que la activan, sea al decirle al biólogo que sus experimentos funcionan y se definen por la presión del mercado y los laboratorios y no por su encono por vencer a un cierto virus, el científico de lo social cosecha el rechazo -o la indiferencia- de cada uno de sus sujetos investigados (Latour 2008:137). La forma más radical de este recurso, según Latour, lo constituye la sociología crítica, que toma la indignación de los actores ante la inverosimilitud de sus explicaciones como la demostración de lo intolerable que es para ellos la verdad de las interpretaciones realizadas (Latour 2008:78).

La sociología que Latour defiende operaría en una estrategia de dos pasos: en un primer paso, el sociólogo parece más bien un clásico antropólogo, dedicándose a 'rastrear', 'mapear', 'describir' las 'controversias', lenguajes, intereses, discursos de los sujetos y escenarios involucrados. Luego, en un segundo paso se buscaría integrar y conectar las 'controversias' y puntos de vista encontrados en el terreno.

Las siguientes tesis, en consonancia con dicha propuesta general, se proponen dar especificidad, defender, ejemplificar, argumentar, sobre soluciones requeridas para sortear estas oposiciones que, a fuerza de repetirse, se han vuelto tan resistentes como problemáticas.

\section{Tesis 2. Los objetos (los no- humanos) deben ser estudiados por la sociología}

La segunda tesis refiere a la necesidad de darle un lugar más amplio y más activo a las entidades no- humanas para explicar las coyunturas y experiencias humanas. Cuando se refiere a objetos y entidades no humanas, por raro que suene al oído sociológico, no se refiere a 'objetos de estudio', o genéricamente lo objetivo y lo subjetivo, sino a llanamente objetos: mesas, sillas, computadoras. Y más ampliamente, a entidades tales que divinidades, microbios, plantas, obras de arte, etc.

Para Latour, las ciencias sociales han dado un paso equivocado al dejar a los objetos al ojo de físicos, químicos e ingenieros. Si para el común de los mortales los semáforos ordenan el tránsito, la Virgen hace caminar tantos kilómetros, y las cebollas hacen llorar, Latour postula que las explicaciones sobre la vida humana deben tener permitido incorporar a estos elementos como factores efectivos en la agencia. Excluirlas conlleva, según Latour, a la introducción de fuerzas invisibles y procesos inverificables para explicar lo social (anulando las metafísicas de los actores y sobrescribiéndolas con las del investigador).

De este modo, cuando las explicaciones sociales intentan dar cuenta de objetos no sociales (objetos naturales o de otra índole), señala Latour que la operación más frecuente es sustituir el objeto no social por uno social que le dio origen: de esta forma, se lleva la descripción a un terreno conocido, con el previo costo de eliminar de la explicación al objeto original (Latour 2000: 109). Para Latour, estas sustituciones no deben darse: cuando un resalte hace frenar a un conductor, Latour prefiere ir al revés de las explicaciones del fetichismo: o el conductor frena, o rompe su auto. De no estar ese montículo, el conductor sigue a toda velocidad. El principio que busca romper es el de la irrealidad de lo no-humano para las explicaciones humanas. Su postulado es de no separar al explicar, no trazar una divisoria entre humanos y no-humanos que luego obligue a reconciliarlos, a unirnos, a intentar conectarlos. De allí numerosos ejemplos de cómo los objetos guían a las personas y las personas a los objetos (Latour 1995: 96). Si en la vida cotidiana están incesantemente y desde siempre ahí juntos, propone aceptar esa 
unidad y realizar descripciones desde ella. Si una persona respeta un semáforo o respeta una orden de un guardia de tránsito, da -al menos en cierta medida- igual. No hay falsa obediencia a uno y obediencia verdadera para con el otro: puede ser falsa o verdadera en cualquiera de ambos casos. La legitimidad del semáforo (y su poder) se nutre de raíces semejantes a las de cualquier otra legitimidad o poder.

\section{Tesis 3. La asimetría entre 'naturaleza' y 'mundo social’ debe ser abandonada}

Latour encuentra el final del siglo XX como un momento donde dos grandes supuestos de la modernidad occidental se encuentran cuestionados: que la naturaleza puede ser completamente dominada por medio de saberes técnicos, y que la explotación y la miseria pueden ser efectivamente reducidas por el socialismo y la intervención estatal (Latour 2007: 25). El primero de estos supuestos, habiendo entrado en crisis tanto por la puesta en evidencia del carácter finito de la naturaleza como proveedora de recursos, como por la recurrencia de catástrofes y complicaciones de origen natural. El segundo de estos supuestos, habiéndose puesto en cuestión por la caída del Muro de Berlín (como imagen del fracaso del modelo soviético) y por las recurrentes crisis que encuentran siempre su solución en el empobrecimiento de millones de personas.

Ante esta perspectiva, Latour cuestiona la cosmovisión moderna que, a su criterio, avanzó gracias a dos operaciones contrapuestas: por un lado, separar conceptualmente la naturaleza del mundo humano, como si se tratara de dos espacios independientes que es posible observar, tratar e investigar aisladamente; por otro, desarrollar innumerables técnicas y saberes para combinar naturaleza y necesidades humanas, tomando elementos de la naturaleza para explotarlos, modificarlos, reformularlos. Esta separaciónrecombinación se traduce luego en división de competencias entre saberes 'naturales' (físicos, biólogos, etc.) y 'sociales' (sociólogos, historiadores, etc.), y actividades 'técnicas' (ingenieros, especialistas, etc.) y 'políticas' (gerentes, funcionarios, etc.). Tal como si una parte de la humanidad se pudiera dedicar a lidiar con la naturaleza, y otra con lo humano, ambos intentando no ser 'contaminados', invadidos, por las incumbencias, personas y lógicas del otro campo. Esta división deja, dice Latour, a la naturaleza con una existencia real pero carente de humanos, y a la política con humanos pero sin realidad (sin más que 'construcción social') (Latour 2004: 54).

A criterio de Latour, esta separación es la que ha entrado en crisis a finales del siglo XX. La superación a estas dificultades vendría de la mano de una simetrización -como ruptura de las jerarquías- entre estos dos 'mundos': dejar entrar sin remordimientos a la naturaleza en la política, y a la política en la técnica. Si la desigualdad en la distribución de recursos, y la abusiva explotación de recursos, se dan ambos a la par y ambos por hombres y naturaleza, propone intentar reformular ambos problemas como un solo problema, partiendo de la afirmación básica de que no hay ni hubo hombres viviendo sin 'naturaleza' (sin alimentos, sin ropas elaboradas de plantas y otras elementos, sin tecnologías materiales de toda índole), y que no hay tampoco para el hombre una naturaleza inexplorada e inexpugnable, sino siempre una naturaleza vivida por personas.

\section{Tesis 4. Lo socialmente construido es real y toda construcción es sólo parcialmente previsible}

En esta tesis, Latour realiza una crítica al significado que con frecuencia se le otorga a la idea de 'construcción' en el marco de señalar el carácter 'construido', 'histórico', de ciertas formaciones o elementos de la vida social (Latour 2008:130). Latour relata cómo con sorpresa las investigaciones en las que señalaba que los hechos científicos eran construcciones sociales eran asimiladas a dos sentidos por él no buscados pero con frecuencia utilizados: por un lado, que ser 'construidos' sería sinónimo de que unas personas pudieron de manera racional disponerlo todo en su sitio de forma ordenada y 
planificada; por otro, que la 'denuncia' de 'construido' haría de esas cosas elementos menos reales.

En este sentido, la idea de 'construcción social' de los hechos es revisada en dos aspectos: respecto al carácter paulatino, falible, complejo, imprevisible, de una construcción, y respecto a la relación de lo construido con el nivel de realismo y verosimilitud de una cosa.

Respecto del primer aspecto, Latour remite a la imagen de una construcción en su sentido literal: la fabricación de un edificio, una casa u otro objeto de ingeniería civil. Dice: "al ver lo que la mayoría de los sociólogos Ilama 'construcción', uno duda de que alguna vez haya construido algo tan simple como una choza, ni hablar de una 'sociedad'" (Latour 2008: 64). En este sentido señala que situados en una obra, 'con los pies en el barro', se hacen patentes dos cosas: que la obra podría continuar en múltiples formas, y sobre todo, que la ejecución de la misma podría fracasar. Que son muchos los elementos que intervienen en la obra más simple, y que todos ellos suponen cambios, coordinaciones, imprevistos y adaptaciones. Un elemento recurrente en la argumentación de Latour a este respecto es el planteo de la necesidad de observar formas, costos y medios de cada acción, transmisión e interacción social. En este sentido, insiste en la necesidad de dar lugar a cada partícipe de las relaciones sociales (humanos y no humanos) en tanto pueden ser en sí mismos modificadores y creadores de efectos. 'No hay información, hay transformación', afirma (Latour 2008: 221).

Respecto del segundo aspecto, cuestiona la convicción por la cual 'construido' sería sinónimo de 'menos real'. Observa que con frecuencia ciertas posiciones 'críticas' parecen haber desmentido la existencia misma de una cosa cuando declaran que han mostrado que se trataba de algo histórica o socialmente construido. Regresando nuevamente sobre la metáfora original (las obras de ingeniería), Latour resalta el hecho de que nadie se preguntaría si un auto, un rascielos o una planta nuclear han sido construidos o no y, mucho menos, si por haber sido 'construidos' son menos reales o menos sólidos que un montículo de tierra creado 'naturalmente' (Latour 2008: 135). Por el contrario, dice Latour, el espacio de la construcción es -en estos campos- allí donde una suma de humanos y no humanos cooperan y se transforman para dar lugar a algo nuevo. En ingeniera, dice Latour, la pregunta es si algo está 'bien construido' o 'bien diseñado', antes que si algo es o no una cosa construida.

Una vez superada la confusión sobre qué es estar construido, lo social -y también los saberes científicos- deben poder responder a la pregunta de si han sido 'bien construidos' o 'mal construidos', 'bien diseñados' o 'mal diseñados', y no caer en lo que llama la absurda opción de tener que elegir entre si un hecho es real o es fabricado (Latour 2008: 134). En el caso de las ciencias naturales, encuentra que es claro que un experimento de laboratorio es el ejercicio de una construcción artificial (buscando librarse de factores azarosos) para la aparición de una verdad buscada; las ciencias sociales, dice Latour, en nada difieren de esta búsqueda de saber intencionado y bien construido, caracteres comunes de la ciencia aplicada moderna en general.

Tesis 5. Que las verdades más 'duras', más reconocidas como 'objetivas', se encuentran en un continuo con saberes menos consolidados, señalados como ideológicos, dudosos, relativos

Con las observaciones que realiza en este sentido, Latour busca redefinir algunas delimitaciones tradicionales sobre la construcción de saber. En primer lugar, plantea la necesidad de mirar, en la historia de la ciencia, con iguales exigencias y procedimientos a los saberes que se sostienen como conocimiento válido y a los saberes que no lo hacen. Latour encuentra que con frecuencias estos estudios se han limitado a 'hacer leña del 
árbol caído', atribuyendo muchas veces problemas a los saberes abandonados que también eran reconocibles en saberes 'vigentes' (Latour 2007: 141).

En segundo lugar, Latour se inscribe en una posición 'realista', reconociéndole sentido a la búsqueda colectiva de 'cuestiones de hecho', es decir, las que habrán de considerarse verdades más objetivas, más incontrastables, más universales, en relación a otras cuestiones que -a falta de lograr dirimirse en alguna dirección- se mantendrán como 'cuestiones de interés' (Latour 2007: 139). Sin embargo, rechaza la separación de ambas cuestiones como si se tratara de productos de búsquedas diferentes. Para Latour, un saber 'bien construido' puede darse (y usualmente se da) bajo presiones de mercado, necesidades históricas, políticas, ideológicas, naturales, entre otras. En este sentido, señala como caso la invención de la píldora anticonceptiva (Latour 2012: 35), resaltando la importancia de la articulación de actores heterogéneos (científicos, sociales, políticos) en la construcción de conocimiento novedoso y relevante.

Por último, en relación a esta tesis, también cabe señalar las indicaciones del autor en cuanto a rechazar una diferencia cualitativa entre el grado de relativo, o el grado de dependiente de perspectivas, del saber en ciencias naturales y en ciencias sociales. Para Latour, un saber 'bien construido' debe poder sostenerse como 'cuestión de hecho' en cualquiera de ambas ramas de conocimiento, a la vez que muestra cómo -al igual que en ciencias sociales- las ciencias naturales revisan constantemente sus cuestiones mientras desde fuera de ellas las mismas son apreciadas como cosas ya conocidas y cerradas (Latour 2008: 168- 169).

\section{Tesis 6. Lo global debe representarse como un nivel tangible}

Para desarrollar esta tesis Latour recurre a la imagen de intentar observar un mundo 'aplanado', en términos de dejar de considerar jerarquías de entidades clasificables como de más alto o más bajo nivel de agregación. Dice en este sentido: "lo macro no se encuentra "encima" ni "debajo" de las interacciones, sino agregado a ellas como otra de sus conexiones, alimentándolas y alimentándose de ellas" (Latour 2008: 255). En estos términos, propone reconocer la mayor relevancia de un cierto sitio por el numero de lugares con los que se conecta, pero siempre tomando estas conexiones como conexiones entre sitios locales.

Lo que de este modo se evita, en concordancia con los objetivos de las tesis anteriores, es que existan puntos en los que las descripciones y explicaciones de lo social se vean interrumpidos para saltar al 'contexto global' (tenga el nombre que fuera... capitalismo global, contexto nacional, estructura social). Lo que busca así Latour es escapar al salto fuera de toda escena, la interrupción de las conexiones identificables y observables. Para el autor, cada conexión tiene un modo de darse -un transporte- y esperablemente también costos de transmisión y mantenimiento. En consecuencia, no es un dato menor de qué modo algo está o no efectivamente conectado con otro sitio, y de qué modo se garantiza y sostiene esa relación. De este modo, no bastará decir que un pueblo pesquero ve limitada su actividad por el capitalismo global. Será necesario ver de qué manera la actividad del pueblo se modificó, qué nuevos actores entraron en escena o produjeron acciones que la modificaron, etc. Igualmente, teorías y construcciones científicas ("capital cultural", "individualismo metodológico", "género") son resituadas en el marco de ser elementos que se generan y viajan por medios específicos: artículos en revistas académicas, computadoras personales, solicitudes de fondo, reimpresiones en manuales, etc. (Latour 2008: 262)

\section{Tesis 7. Lo local no es lo solamente aquí y ahora}

Como contraparte de la tesis anterior, dice Latour, los lugares locales ya no puedan ser tomados como micromundos cerrados, contenidos, listos para mostrar su verdad evidente 
y presente. Las interacciones cara a cara, y las observaciones, mediciones y análisis en general, deberán poder dar cuenta de las largas cadenas de fabricación, condicionamiento, e interdependencia en general que las une con otros espacios, actores, recursos. Si se analiza una condición educativa, se encontrará que el aula en la que se 'sitúa' la situación, ha sido construida hace décadas en condiciones y con prioridades en principio no tan visibles pero potencialmente operantes y vigentes. Lo mismo se aplica para las opiniones dadas por los alumnos, su lenguaje, y la larga lista de cosas que no han sido construidas instantáneamente con la situación local observada. En consecuencia, a la vez que lo macro sólo ocurre en lugares concretos, estos sitios particulares no pueden ser comprendidos aisladamente, sin dar cuenta al menos en alguna medida de sus conexiones y dependencia con otros sitios.

Por último, cabe retomar en relación a la cuestión local-global el problema de la escala, vinculado a estas dos últimas tesis. Latour remarca como una facultad de los actores la posibilidad de aludir a sus realidades saltando entre marcos de diferentes escalas (ej. nacional, local, personal). Esta facultad, según Latour, debe ser emulada y retomada por el investigador, evitando asumir una posición 'fija' de 'zoom', una escala única en la que lo social deba ser descripto. A criterio de Latour, para poder seguir el sentido y la acción de los actores, es necesario poder también perseguir sus marcos y acomodarse a los diferentes 'zooms' que ellos realizan cotidiana y constantemente en sus interpretaciones y descripciones (Latour 2008: 265). Respecto a la discusión micro- macro que esta salvedad alude, queda de esta forma separada en dos asuntos independiente la definición del fenómeno respecto de su observación: por una parte, existe la distribución de las conexiones entre los sitios (todos en un mismo nivel, pudiendo estar más o menos conectados), y por otra, existe la escala de presentación, el 'zoom' operativo con el que los actores o los investigadores se dispongan a observarlos.

\section{Conclusiones}

Por medio de sus obras, Latour aporta en estas tesis aquí presentadas un conjunto de críticas a varios elementos centrales de la teoría social contemporánea.

Antes de resumir y comentar, a modo de cierre, tres elementos centrales en su argumentación, cabe señalar como problemático en su propuesta -para una teoría general- lo que parece manifestarse como una marcada preferencia por abordajes cualitativos (por el texto o por la red) y situados en el terreno. Si bien estas estrategias permitirían más adecuadamente -según Latour- captar los discursos y saberes de los actores, parecen poco compatibles con señalamientos en torno a una creciente necesidad de integrar en forma cada vez más frecuente y compleja fuentes de información y técnicas de múltiples niveles y cualidades heterogéneas. En este sentido, Latour parecería mantenerse en un clivaje cualitativo- cuantitativo que ha perdido en buena medida actualidad y relevancia (Gallart 1992; Lozares et al. 1998; Sierra 2003).

En términos de aportes, en primer lugar se ha visto que Latour cuestiona los análisis que ponen el centro en los 'factores sociales' (o las relaciones de poder) que operan sobre las actividades humanas. Sin embargo, no realiza esta crítica invocando la necesidad de una neutralidad sociológica o un distanciamiento entre ciencia y política, sino por el contrario acusando a estas corrientes de tener un comportamiento paternalista y soberbio respecto de las realidades o actores que buscan explicar o transformar. En este sentido, acusa a la sociología clásica, y a la sociología crítica de Bourdieu, de 'saber demasiado', y al mismo tiempo, de aprender demasiado poco en cada investigación. En términos políticos, considera que por estos medios sólo se convence a los actores de su falta de capacidades para comprender y de lo falso de sus vidas, es decir, hace de los dominados seres pasivos que deben aprender de la ciencia la realidad de sus vidas. En términos científicos, para Latour este proceder conduce a un saber estanco que parece ya haber descubierto cuanto había por descubrir, sumado a la inconsistencia de que -según Latour- la ciencia de 
Bourdieu se presenta a sí misma como una excepción única, dándose como un saber objetivo y acabado de la realidad y no como un mero emergente de las relaciones de poder, tal y como se describe al resto de las creaciones humanas ${ }^{3}$. Al menos parcialmente, y sin que por ello se sugiera abandonar las investigaciones sobre la dominación y las formas del poder, la crítica parece productiva si se busca elaborar una sociología de agentes más activos, o de un mundo social reconocible a la vez como real (superar el dualismo que divide entre lo popular e ilusorio y lo científico y verdadero).

En segundo lugar, para la sociología la separación entre sujetos (personas) y objetos (cosas) fue una operación fundacional que se encontró tradicionalmente fuera de cuestión. La propuesta de Latour de darle un lugar activo en la agencia a toda suerte de entidades no- humanas cuestiona en forma directa la noción de 'reificación', por la cual la sociología proponía considerar a todo cuanto componía el entorno de la vida humana una construcción con poderes sólo aparentes. En este sentido, algunas investigaciones han considerado en las últimas décadas objetos y seres 'imaginarios' como entidades sociológicamente activas y asequibles, tanto antes como después de los textos de Latour, con resultados interesantes (Pollner 1989; Domínguez Rubio 2008).

En tercer lugar, relativizar la noción de naturaleza como algo ajeno a lo social permite en la articulación de Latour cuestionar la operación sociológica básica de 'desnaturalizar' lo social. Latour sugiere algo así como permitirse socializar lo natural y naturalizar lo social. Lo primero, en términos de dejar entrar a la naturaleza, a las ciencias naturales y a la técnica lícitamente en el mundo de lo social y de lo político; abandonar la pretensión de verlos como esferas cerradas. Lo segundo, en términos de aceptar lo socialmente construido como algo real, y dar por ciertas las ontologías propias de cada ámbito humano, tales que las obras artísticas, las divinidades religiosas, las pasiones deportivas, entre otras. Asimismo, la iniciativa de Latour de integrar lo natural a lo social puede enmarcarse en el espacio más amplio del Ilamado 'giro corporal' (Sheets- Johnstone 1990; Shilling 2003), que se fue estableciendo primero al extenderse las investigaciones de ciencia social del nivel de las normas y las ideas al nivel de las 'prácticas' (Bourdieu 2007) y de los 'cuerpos' (Foucault 1995), y más contemporáneamente, continuando ese movimiento hacia aspectos cada vez más específicos de lo corporal y sus dinámicas sociales (Sánchez García 2008; Olszewski 2008).

Por último, es posible señalar que si bien el objetivo de Latour de fundar una nueva sociología a partir de sus hallazgos en el campo de los estudios de la ciencia resulta en cierto modo un proyecto demasiado ambicioso, sí es en cambio reconocible como un logro alcanzado -en el intento de lo primero- el aportar elementos para renovar y cuestionar prácticas y nociones consolidadas en la disciplina, dando así algunas claves para poder extender la mirada sociológica sobre espacios antes marginados o mayormente postergados. RM

\section{Bibliografía}

Bourdieu, P. (2007). El sentido práctico. Buenos Aires: Siglo XXI. Bourdieu, P. (2008). Homo academicus. Buenos Aires: Siglo XXI.

Domínguez Rubio, F. (2008). La cuestión del objeto como cuestión sociológica. En T. Sánchez Criado (Ed.), Tecnogénesis. La construcción técnica de las ecologías humanas (pp. 79-112). Madrid: AIBR.

Foucault, M. (1995). Vigilar y castigar. México D.F.: Siglo XXI.

\footnotetext{
${ }^{3}$ En términos de Bourdieu esto se explica debido a que los condicionantes estructurales de la acción pueden ser relajados mientras sean identificados. Al ser la sociología la vía para tal identificación, el sociólogo que logra aplicar su método sobre sí mismo, podría potencialmente actual con un margen especial de libertad respecto a estos condicionamientos.
} 
Gallart, M.A. (1992). La integración de métodos y la metodología cualitativa. Una reflexión desde la práctica de la investigación. En F. Forni, M.A. Gallart \& I. Vasilachis, Métodos cualitativos II. La práctica de la investigación (pp. 107- 152). Buenos Aires: CEAL.

Kindley, E. (2010). Creature of habitus: Latour on Bourdieu. Recuperado de < http:// wehaveneverbeenblogging.blogspot.com.ar/2009/12/ creature- of- habituslatour- on- bourdieu.html> (28/04/2013)

Latour, B. (1992). Ciencia en acción. Barcelona: Labor.

Latour, B. (1995). ¿Tienen historia los objetos? el encuentro de Pasteur y de Whitehead en un baño de ácido láctico. Isegoría: Revista de filosofía moral y política, 12, 92- 109.

Latour, B. (2000). When Things Strike Back: a Possible Contribution of 'Science Studies' to the Social Sciences. British Journal of Sociology, 51(1), 107-123.

Latour, B. (2004). Politics of Nature. Cambridge, Mass: Harvard University Press. [1999]

Latour, B. (2007). Nunca fuimos modernos. Buenos Aires: Siglo XXI. [1991]

Latour, B. (2008). Reensamblar lo social. Buenos Aires: Manantial. [2005]

Latour, B. (2012). Cogitamus. Seis cartas sobre las humanidades científicas. Buenos Aires: Paidós. [2010]

López Pérez, R. (2010). Para una conceptualización del constructivismo. Revista Mad, 23, 25- 30.

Loredo Narciandi, J. (2009). ¿Sujetos o "actantes"? El constructivismo de Latour y la psicología constructivista. Revista de Antropología Iberoamericana. 4(1), 113- 136.

Lozares C., Martín A. \& López P. (1998). El tratamiento multiestratégico en la investigación sociológica. Papers, 55, 27-43.

Olszewski, B. (2008). El cuerpo del baile: The Kinetic and Social Fundaments of Tango. Body \& Society, 14(2), 63-81.

Pollner, M. (1989). Divine Relations, Social Relations, and Well-Being. Journal of Health and Social Behavior, 30(1), 92-104.

Sánchez García, R. (2008). Análisis etnometodológico sobre el dinamismo del habitus en Bourdieu y Elias dentro del desarrollo de actividades corporales. Revista Española de Investigaciones Sociológicas (Reis), 124, 209- 231.

Sánchez-Criado, T. (2011). Imitación, oposición e innovación de las formas sociales: Finitud e infinitud en Las Leyes Sociales de Gabriel Tarde. Athenea Digital, 11 (1), 241- 254.

Schinkel W. (2007). Sociological Discourse of the Relational: the Cases of Bourdieu \& Latour. The Sociological Review, 55(4), 707- 729.

Sheets- Johnstone, M. (1990). The Roots of Thinking. Philadelphia, Penn: Temple University Press.

Shilling, C. (2003). The Body and Social Theory. Londres: Sage.

Sierra, E. (2003). Nuevos elementos para la reflexión metodológica en sociología. Del debate cuantitativo/ cualitativo al dato complejo. Papers, 70, 57-81.

Wuggenig, U. (2008). Crítica paradójica. (Raúl Sánchez Cedillo, trad.). Recuperado de <http:// eipcp.net/ transversal/ 0808/ wuggenig/ es>. (28/04/2013)

\section{Sobre el autor}

Pablo De Grande es investigador del Instituto de Investigación en Ciencias Sociales de la Universidad del Salvador, Argentina. Doctor en Humanidades en la Universidad Nacional de Quilmes, Argentina. Entre sus líneas de investigación se cuentan: sociabilidad, redes personales, sociología de la infancia, pobreza.

Contacto

Hipólito Yrigoyen 2441, CP. C1089AAU

Ciudad de Buenos Aires, Argentina

pablodg@gmail.com

Recibido: Abril 2013

Aceptado: Junio 2013 